\title{
PROSTHETIC JOINT IMFEETION DUE TO HAEMOPHILUS APHROPHILUS
}

\author{
*DR. HELEN CHESTERFIELD, MBBS, MRCP \\ United Kingdom \\ **DR. ABDOLALI ASSARIAN, MD, MRCSED \\ United Kingdom \\ DR. ANN PALLETT, MBBS, FRCPATH \\ United Kingdom \\ Dr. Jeremy Latham, FRCS (Ortho) \\ United Kingdom
}

\begin{tabular}{ll} 
Article received on: & $25 / 01 / 2007$ \\
\hline Accepted for publication: & $20 / 08 / 2007$
\end{tabular}

\begin{abstract}
A case of prosthetic joint infection due to Haemophilus aphrophilus is presented. A 76-year-old woman, with a long history of pain in her left hip and raised inflammatory markers, underwent prosthetic joint excision. Six samples of pus and tissue were taken from the joint and Haemophilus aphrophilus was cultured from 3 of these specimens. We review the clinical and microbiological findings. Treatment with ciprofloxacin after removal of the prosthesis resulted in clinical improvement.
\end{abstract}

Key words: $\quad$ H. aphrophilus, prosthetic joint infection, infectious arthritis.

\section{INTRODUCTION}

Haemophilus aphrophilus is an uncommon gramnegative coccobacillus that was first described by Khairat in 1940 following a case of fatal endocarditis ${ }^{1}$. It is rarely associated with bone and joint infection and to our knowledge this is the first reported case of prosthetic joint infection due to this microorganism.

\section{CASE HISTORY}

A 76-year-old woman with a left hip prosthesis was admitted to Southampton General Hospital in June 2001 with a discharging sinus from her left hip. She had a history of severe osteoarthritis and had undergone left total hip replacement in October 1994 and subsequently right total hip replacement in March 1995. She started to experience problems with her left hip in August 1995 when she was admitted with pain and weakness in her left leg. There was no history of trauma. Two weeks before admission she had complained of a 'flu like illness' for which she had not sought treatment.

On examination there was stiffness around the hip joint with no signs of nerve root compression in the lower extremities. She was afebrile. Investigations revealed a 
raised ESR of $90 \mathrm{~mm} / \mathrm{h}$ and a normal white cell count. Blood cultures were negative on two different occasions. Plain X-rays were unremarkable. Whole body isotope bones scan showed increased uptake around the acetabular component of the left hip. There was normal activity around the left femoral component and the right hip. An ultrasound revealed a small amount of fluid, which was aspirated and sent for culture with negative results. She was diagnosed with iliopsoas bursitis although it was not possible to exclude a low-grade infection. However the patient improved clinically with analgesia and was discharged.

In May 1997 the patient returned to the orthopaedic outpatient clinic complaining of increased pain in the left hip. A plain film revealed erosive changes around both the acetabular and femoral components and a repeat bone scan once again showed increased activity in the left hip. Her ESR was raised at $90 \mathrm{~mm} / \mathrm{h}$ and a diagnosis of low-grade infection was made. She was commenced on cephradine $500 \mathrm{mgs}$ qds and her symptoms improved. She continued to take antibiotics for the next 4 years with reasonable control of her symptoms. However it was noted that her inflammatory markers did not improve and her ESR remained above $90 \mathrm{~mm} / \mathrm{h}$.

In March 2001 she was noted to have swelling and increased pain in the medial and posterior aspect of the left thigh and the antibiotics were stopped. By June she had developed a discharging sinus. A superficial swab revealed only skin flora and she was treated conservatively. Antibiotics were not restarted. In November she underwent excision of her left hip prosthesis, which revealed frank pus inside the joint. Six intraoperative specimens were taken, including joint fluid, acetabular membrane, femoral tissue and sinus material, and sent for microscopy and culture.

Gram stain of the femoral tissue revealed numerous white cells but no organisms were seen. The specimens were inoculated on blood, chocolate and fastidious anaerobic agar and incubated under both 5\% $\mathrm{CO} 2$ and an anaerobic atmosphere at $37^{\circ} \mathrm{C}$. After 24 hours, growth of a catalase and oxidase negative organism was detected on the chocolate plate from $3 / 6$ specimens (joint fluid and acetabular membrane). Gram staining revealed a small Gram negative coccobacillus. The colonies were small, convex and glistening, and required $\mathrm{X}$ but not $\mathrm{V}$ factor. The organism was identified using API 20E systems as a Haemophilus aphrophilus and a test for B-lactamase production using a cefinase disk was negative. The organism was susceptible to amoxycillin, amoxycillin/clavulanic acid, cefotaxime, chloramphenicol, ciprofloxacin, trimethoprim, tetracycline and neomycin using the disk diffusion method. Minimum inhibitory concentrations (MICs) of amoxycillin (MIC= $0.75 \mathrm{mg} / /)$ and ciprofloxacin (MIC $=0.016 \mathrm{mg} / \mathrm{l})$ were determined by means of the $E$ test. (AB Biodisk, Solna, Sweden).

The patient was treated with ciprofloxacin $(750 \mathrm{mg}$ orally 12 hourly) for 6 weeks, and at follow up was well and symptom free. Her ESR which had been above $90 \mathrm{~mm} / \mathrm{h}$ for seven years returned to normal, and a new prosthetic joint, which was inserted several weeks later, is functioning well to date.

\section{DISCUSSION}

Haemophilus spp. causes $<1 \%$ of all cases of bacterial septic arthritis in adults, and of these almost all are due to Haemophilus influenzae. Only 3 cases of septic arthritis due to Haemophilus aprophilus have been reported in the medical literature; 2 were described by Page and King in $1966^{2}$, with a further case report in $1994^{3}$. To the best of our knowledge this is the first report of $\mathrm{H}$. aphrophilus causing prosthetic joint infection.

$\mathrm{H}$. aphrophilus is a commensal of the human oropharynx with a reported incidence of $35 \%$ from gingival scrapings and interdental specimens from healthy adults ${ }^{4}$ and a 1.5 
$\%$ incidence in respiratory specimens of various types ${ }^{5}$. Although some infections probably arise from contiguous extension from their normal habitat in the oral cavity, most infections due to $H$. aphrophilus result from haematogenous dissemination and seeding of distal sites $^{6}$. It has been suggested that transient bacteraemia following dental manipulation/disease ${ }^{7}$ or upper respiratory tract symptoms can lead to seeding of the bacterium to other tissues. The source of infection in our case may have been the upper respiratory tract. A transient bacteraemia may have occurred during the patients' 'flu-like' illness, which seeded to her hip joint. It has also been associated with animal bites, especially dogs and cats $^{8}$. There was no evidence of dental disease or close contact with animals in our patient.

Infections other than septic arthritis with $\mathrm{H}$. aphrophilus have been well described, with endocarditis and brain abscess being the most common. Meningitis, bacteraemia, wound infection, pulmonary infection and vertebral osteomyelitis have also been reported ${ }^{9-16}$. It appears to be a bacterium of low pathogenicity, which causes disease only in the presence of a predisposing condition or tissue damage ${ }^{17}$. The low incidence of infection with $\mathrm{H}$. aphrophilus may be due to the fastidious and slow growth of the organism, leading to its infrequent isolation, however the quality of specimen received in the microbiology laboratory may also play a part. In our case the organism was only isolated once tissue specimens from the joint were cultured. Superficial swabs of the discharging sinus sent on a previous occasion revealed only skin flora.

In cases of osteomyelitis and septic arthritis, once the organism has been isolated it appears to be relatively easy to treat with antibiotics, often with a penicillin or cephalosporin. In a review of 15 cases of vertebral osteomyelitis due to $\mathrm{H}$. aphrophilus ${ }^{9}$, treatment in hospitals included a penicillin or a cephalosporin in 11/15 cases. After 1990 fluoroquinolones were used as monotherapy in 4/5 cases and in one case was used in combination with a third generation cephalosporin. The duration of treatment ranged from 1-3 months in most cases and the outcome was favourable in all. In the 3 cases of septic arthritis due to $\mathrm{H}$. aphrophilus reported in the literature, one case received surgical treatment only ${ }^{2}$, and the other 2 received either penicillin or a cephalosporin ${ }^{2,3}$. Recovery was seen in all 3 cases. However there have been reports of clinical failure of treatment with third generation cephalosporins, and a case of endocarditis failed to resolve until treatment was changed from cefotaxime and netilmicin to ciprofloxacin ${ }^{13}$.

\section{CONCLUSION}

In summary, on the basis of this review, prosthetic joint infection caused by H.aphrophilus is unusual and to our knowledge has not been reported before. Treatment with ciprofloxacin following removal of the prosthesis led to complete recovery. The importance of sending multiple operative specimens to facilitate a microbiological diagnosis cannot be overestimated.

\section{REFERENCES}

1. Khairat $O$. Endocarditis due to a new species of Haem ophilus. J Pathol Bacteriol. 1940; 50: 497 - 450.

2. Page MI, King EO. Infections due to Actinobacillus actinomycetacomitans and Haemophilus aphrophilus. New England Journal of Medicine. 1966; 275 (4): 181-8.

3. Merino D, Saavedra J, Pujol E, Vega D, Colchero J, Boto A, Pascual L. Haemophilus aphrophilus as a rare cause of arthritis. Clinical Infectious Diseases. 1994; 19 (2): $320-2$.

4. Kraut MS, Attebury HR, Finegold SM, Sutter VL. Detection of Haemophilus aphrophilus in the Human Oral Flora with a Selective Medium. Journal of Infectious Diseases. 1972; 126 (2): 189-192.

5. Bierger C, Brewer NS, Washington JA II. Haemophilus aphrophilus: a microbiologic and clinical review and report of 42 cases. Medicine. 1974; 75 (4): 345-55. 
6. Janda WM. The 'HACEK' group; enigmatic fastidious Gram-negative bacilli. Reviews in Medical Microbiology. 1999; 10 (1): 37-50.

7. Root TE, Silva EA, Edwards LD, Topp JH. Haemophilus aphrophilus endocarditis with a probable primary dental focus of infection. Chest. 1981; 80 (1): 109-10.

8. Varghese R, Melo JC, Barnwell P, Chun CH, Raff MJ. Endocarditis due to Haemophilus aphrophilus: a report of a case with possible transmission from dog to man. Chest. 197772 (5): $680-2$.

9. Colson P, La Scola B, Champsaur P. Vertebral infections caused by.Haemophilus aphrophilus: case report and review. Clinical Microbiology \& Infection. 2001;7 (3): 10713.

10. Hung CC, Hsueh PR, Chen YC, Fang CT, Chang SC Luh KT, Hsieh WC. Haemophilus aphrophilus bacteraemia complicated with vertebral osteomyelitis and spinal epidural abscess in a patient with liver cirrhosis. Journal of Infection. 1997; 35 (3): 304-8.

11. O'Driscoll JC, Keene GS, Weinbren MJ, Johnson AP, Palepou MF, George RC. Haemophilus aphrophilus discitis and vertebral osteomyelitis. Scandinavian
Journal of Infectious Diseases. 1995; 27 (3): 291-3.

12. Nahass RG, Cook S, Weinstein MP. Vertebral osteomyelitis due to Haemophilus aphrophilus: treatment with ceftriaxone. Journal of Infectious Diseases. 1989; 159 (4):811-2.

13. Dawson SJ, White LA. Treatment of Haemophilus aphrophilus endocarditis with ciprofloxacin. Journal of Infection. 1992; 24 (3): 317-20.

14. Bejuk KD, Kuzman I, Soldo I, Kuzmanovic N, PopovicUroic T. Vertebral Osteomyelitis caused by Haemophilus Aphrophilus. Euro J Clin Microbiol Infect Dis. 1993;12 (8):643-4.

15. White CB, Lampe RM, Copland RL, and Morrison RE. Soft Tissue Infection Associated with Haemophilus Aphrophilus. Pediatrics. 1981; 67 (3): $434-435$.

16. Crawford SA, Evans JA, Crawford GE. Necrotizing fasciitis Associated with Haemophilus aphrophilus. Case Report. Arch Intern Med. 1978; 138 :1714-1715.

17. Mandell GL, Douglas RG Jr, Bennett JE, Eds. Principles and practice of infectious diseases. $3^{\text {rd }}$ ed: New York: Churchill Livingstone, 1990.

\section{Follow the right course for definite success}

\section{Shula Tahu}

